\title{
Electroencephalography and Brain Imaging Patterns in Children with Acute Encephalopathy
}

Ebru Arhan, Yılmaz Akbas*, Kürşad Aydın, Tuğba Hırfanoglu, Ayse Serdaroglu and Zeynep Ozturk

Gazi University, Faculty of Medicine, Pediatric Neurology Department, Turkey

\begin{abstract}
Background: The electroencephalographic patterns can be associated with brain imaging and outcome in children with acute encephalopathy. A rigorous association of electroencephalography and imaging findings and outcome of pediatric encephalopathy is lacking.

Material and method: We performed a retrospective review of clinical, electroencephalography and imaging data of forty-nine children with electroencephalography pattern of diffuse encephalopathy.

Results: The most prevalent etiological group was the metabolic group. The most common electroencephalography finding was isolated continuous slowing of background activity. Theta pattern was significantly associated with brain atrophy and with toxic encephalopathy, theta/delta pattern with white matter abnormalities and viral encephalitis. Patients with a theta/delta pattern was more likely require intensive care others, whereas those with FIRDA didn't need intensive care.
\end{abstract}

Conclusıon: This study highlights that electroencephalography-imaging when added to the clinical data may help clinicians in the diagnosis, and hence appropiate treatment of pediatric patients with encephalopathy.

Keywords: Encephalopathy; Pediatric; EEG patterns; Brain imaging

\section{Introduction}

Acute encephalopathy is a state of global brain dysfunction, which arises as a result of different combinations of pathological conditions such as infections or toxic, metabolic,and/or brain structural derangements. Diagnosis is optimally reached by melding clinical, electroencephalography (EEG), and neuroimaging features. The EEG is a sensitive but nonspecific tool for pediatric encephalopathies. The EEG in acute encephalopathy generally reveals a non-epileptiform disturbance such as slowing of background activity with or without presence of triphasic waves (TWs) and frontal intermittent rhythmic delta activity (FIRDA) [1-3]. The general rules and simple measures of the EEG remain the same for adults and children in many of the common encephalopathies. However, they are not extensively studied in children.

The association between specific EEG patterns and circumscribed anatomical lesions has been described in both animal models and in human studies [3,4]. The EEG and brain magnetic resonance imaging (MRI) patterns have been recently described in a number of adult studies [5,6]. Despite these observations in adult and experimental studies, a rigorous classification of EEG patterns, imaging findings and underlying causes of pediatric encephalopathy is lacking. As a first step to systematically study this, we decided to analyze EEG and brain imaging in our cohort of pediatric patients with encephalopathy.

The aim of this study was to evaluate the clinical profile and determine associations between EEG patterns and brain imaging findings in pediatric patients with acute encephalopathy.

\section{Methods}

\section{Patient selection and data collection}

This study was performed at Gazi University Faculty of Medicine, Epilepsy Center. All EEG records with an EEG pattern of diffuse encephalopathy during a period of years between 2012 and 2015 were identified from the database of the routine EEG laboratory at Gazi
University Epilepsy Center. After the identification of EEG's, the clinical data of the patients were retrospectively collected and analyzed from hospital medical records. This study was approved by the local ethics committee of Gazi University Faculty of Medicine.

\section{Electrophysiological data}

Electroencephalograms were recorded with silver-silver chloride disk scalp electrodes placed according to the international 1020 system. All patients had at least a spot EEG for 20 min or more. EEGs had been originally evaluated and interpreted by one of the electroencephalographers blinded to the history. Each record was then reread and classified by one of these electroencephalographers (EA); into isolated continuous slowing of background activity (theta, theta/ delta, or delta activity) and patterns with slowing background activity with episodic transients (TWs or FIRDA). Theta activity was defined as generalized slow background activity with a frequency of $4-7 \mathrm{~Hz}$ and amplitudes of $>40 \mu \mathrm{V}$ without intrusions of delta $(<4 \mathrm{~Hz})$ or alpha activity $(8-13 \mathrm{~Hz})$ for $<20 \%$ of recording during wakefulness) (Figure 1). Theta/delta activity was defined as generalized slow background activity of 4-7 Hz and amplitudes of $>80 \mu \mathrm{V}$ with intrusion of alpha activity $(8-13 \mathrm{~Hz})$ for $<20 \%$ and intermixed with delta activity $(<4$ $\mathrm{Hz}$ ) in $20-50 \%$ of recording during drowsiness or arousal (Figure 2). Delta activity was defined as generalized background activity of $<4 \mathrm{~Hz}$ and amplitudes of $>80 \mu \mathrm{V}$ with intrusion of theta or alpha activity for $<20 \%$ of recording during drowsiness or arousal (Figure 3 ). TWs were

*Corresponding author: Yılmaz Akbas, Gazi University Faculty of Medicine Pediatric Neurology Department, 10 th Floor Besevler, Ankara-Turkey, Tel: +90312-2025608; Fax: +90-312-2150143; E-mail: mberf@hotmail.com

Received May 08, 2016; Accepted June 13, 2016 ; Published June 20, 2016

Citation: Arhan E, Akbas Y, Aydın K, Hırfanoglu T, Serdaroglu A, et al. (2016) Electroencephalography and Braın Imagıng Patterns in Chıldren with Acute Encephalopathy. J Neurol Neurophysiol 7: 378. doi:10.4172/2155-9562.1000378

Copyright: $\odot 2016$ Arhan E, et al. This is an open-access article distributed under the terms of the Creative Commons Attribution License, which permits unrestricted use, distribution, and reproduction in any medium, provided the original author and source are credited. 
Citation: Arhan E, Akbas Y, Aydın K, Hırfanoglu T, Serdaroglu A, et al. (2016) Electroencephalography and Braın Imagıng Patterns in Chıldren with Acute Encephalopathy. J Neurol Neurophysiol 7: 378. doi:10.4172/2155-9562.1000378
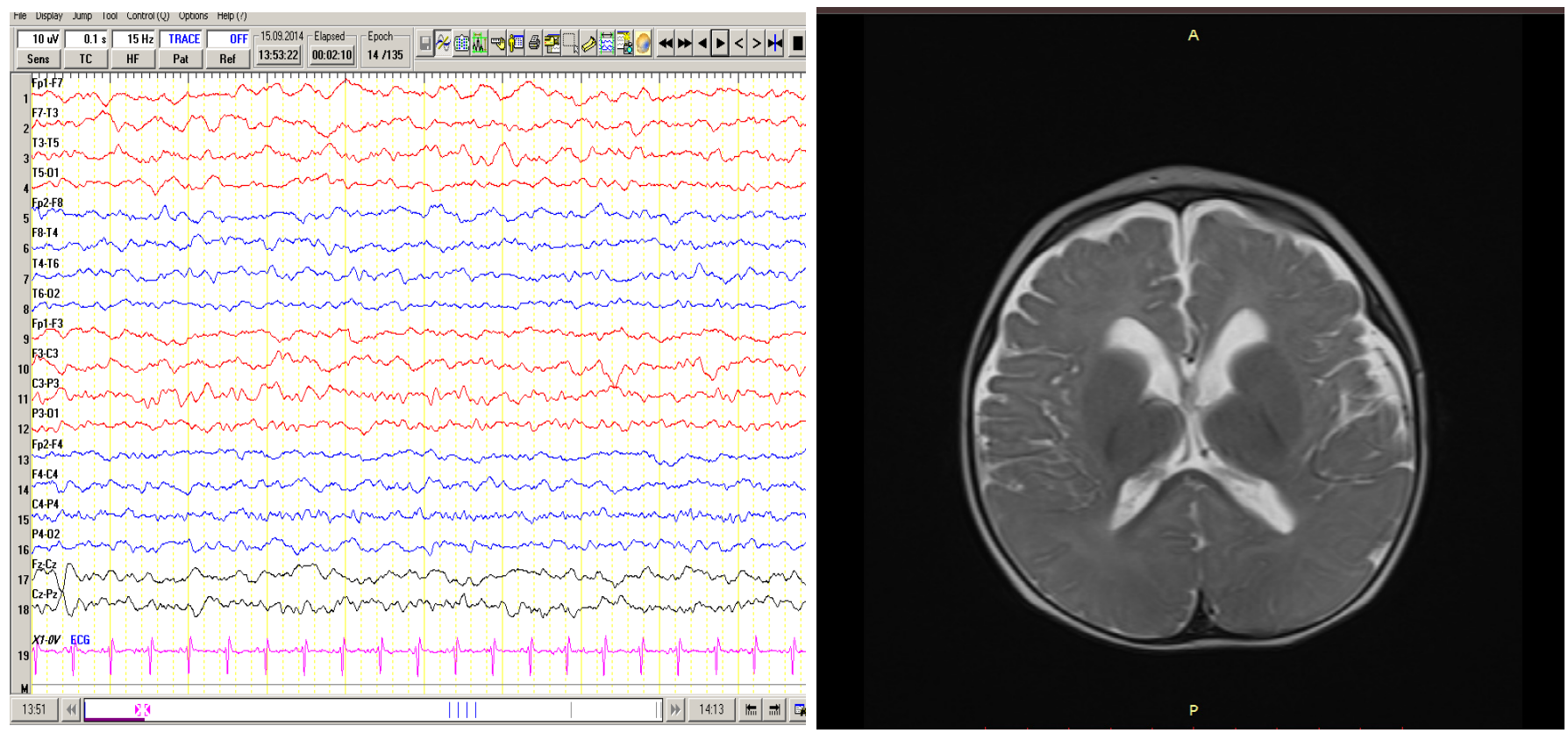

Figure 1: Theta activity in a patient with marked atrophy diagnosed with inborn metabolic disorder. Axial MRI revealing bilateral frontotemporal atrophy. The EEG shows a generalized slow background activity with a frequency of $4-7 \mathrm{~Hz}$ and amplitudes of $>40 \mu \mathrm{V}$ with intrusions of delta (<4 $\mathrm{Hz})$ or alpha activity $(8-13 \mathrm{~Hz}$ ).
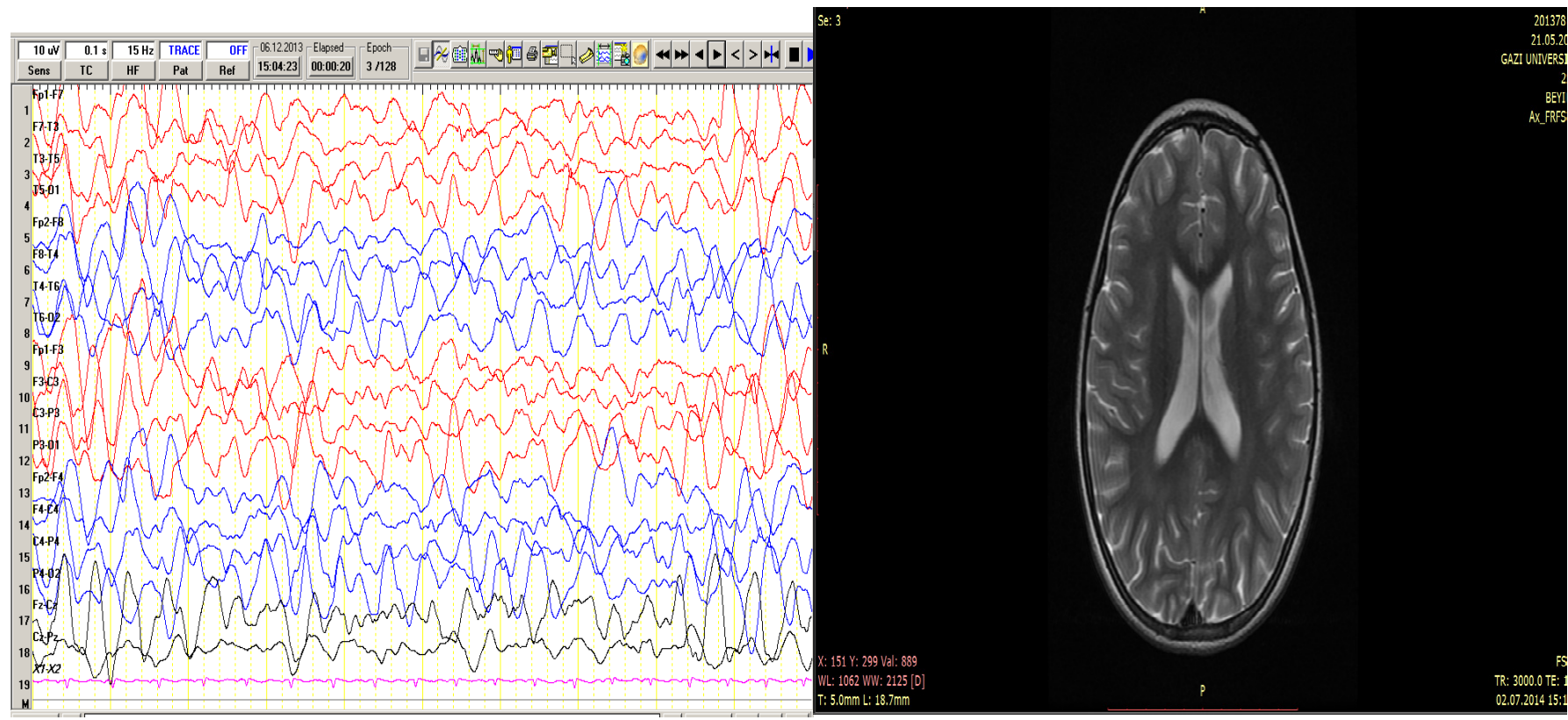

Figure 2: Theta/delta activity in a patient with $\mathrm{H} 1 \mathrm{~N} 1$ triggered acute necrotizing encephalopathy with White matter involvement. MRI shows periventricular white matter changes. The EEG reveals a generalized slow background activity of 4-7 Hz and amplitudes of $>80 \mu \mathrm{V}$ with intrusion of alpha activity (8-13 $\mathrm{Hz})$.

defined as repetitive electrographic elements consisting of three phases, each longer than the preceding one: a surface positive high-amplitude $(>70 \mu \mathrm{V})$ wave preceded and followed by negative waves with smaller amplitude [7,8]. FIRDA was defined as a repetitive appearance of rhythmic slow waves with a frequency $<4 \mathrm{~Hz}$ with a frontal predilection (Figure 4) [1]. In patients with TWs or FIRDA, slowing of background activity was assessed as mentioned above. EEG with epileptiform discharges, burst supression, flat line EEG, spindle or alpha coma were excluded.

\section{Clinical data}

Patients' medical records were retrieved and reviewed to extract demographic information, etiology, Glascow Coma Scale and length of hospital stay. Demographic and clinical characteristics are summarized in Table 1.

\section{Neuroimaging}

All patients had brain imaging. The brain MRIs were obtained with 
Citation: Arhan E, Akbas Y, Aydın K, Hırfanoglu T, Serdaroglu A, et al. (2016) Electroencephalography and Braın Imagıng Patterns in Chıldren with Acute Encephalopathy. J Neurol Neurophysiol 7: 378. doi:10.4172/2155-9562.1000378
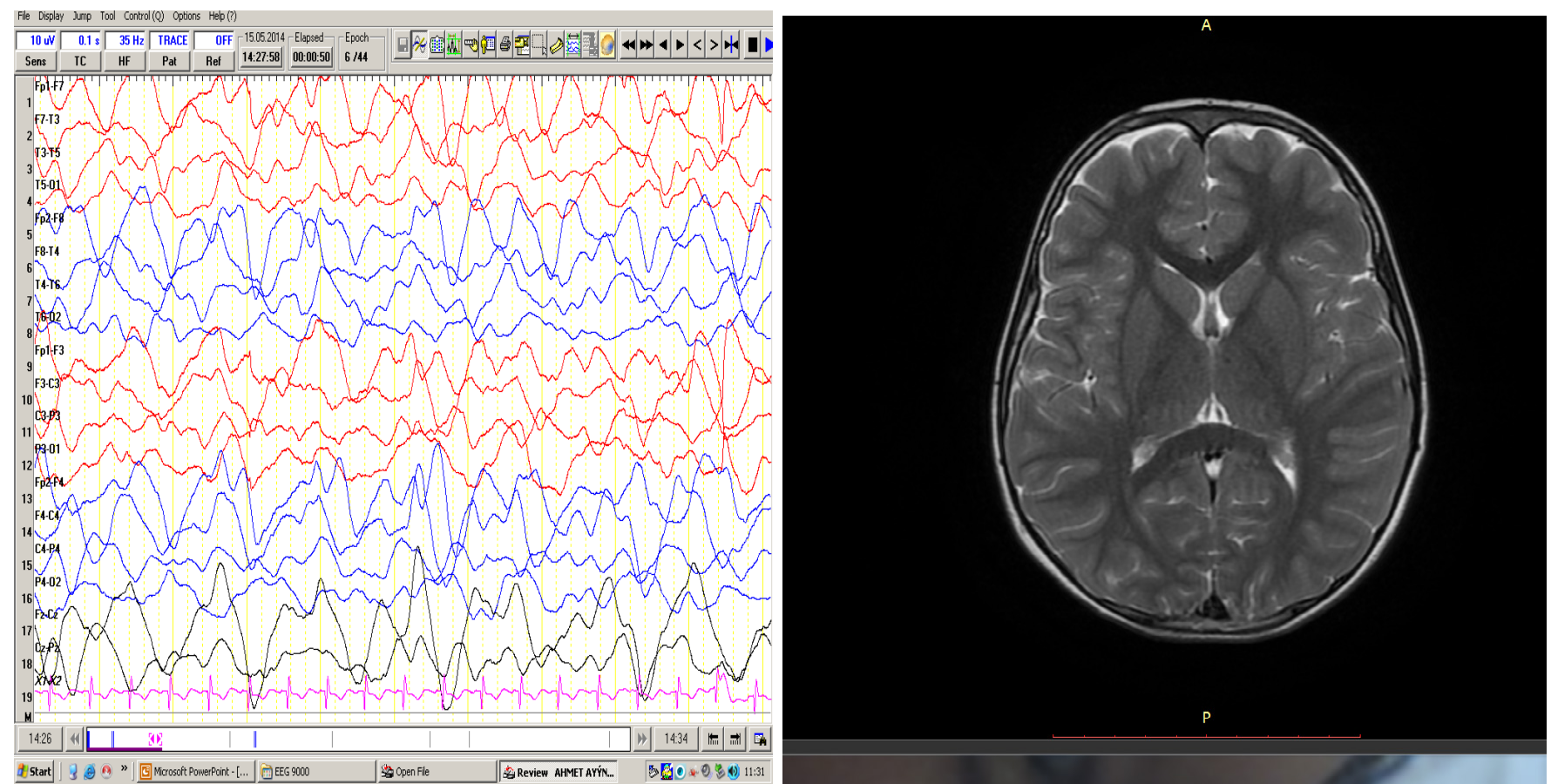

Figure 3: Delta slowing in a patient with unknown drug addiction. MRI at the time of EEG is normal. The EEG shows generalized background activity of $<4 \mathrm{~Hz}$ and amplitudes of $>80 \mu \vee$ with intrusion of theta activity.

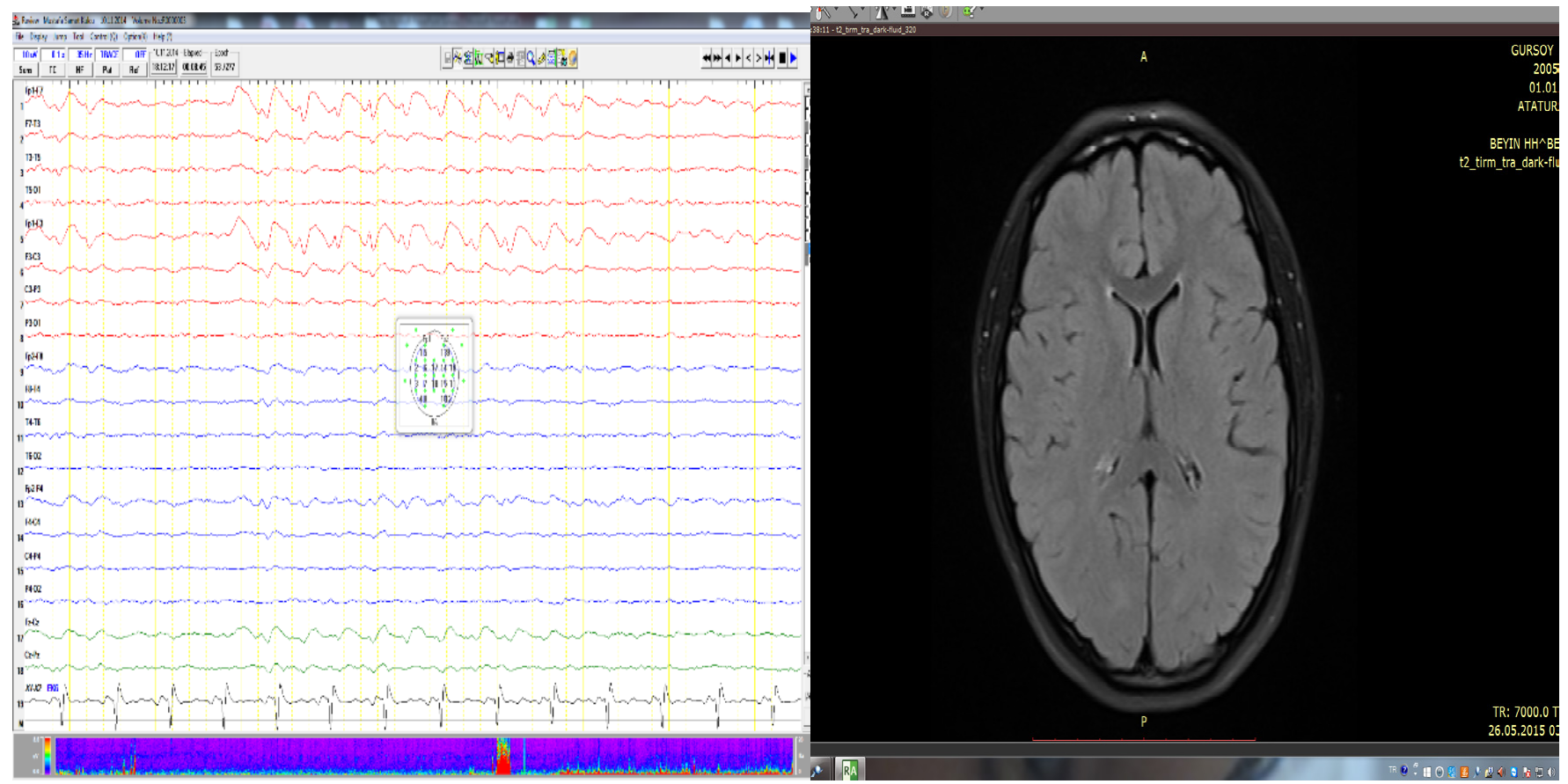

Figure 4: Frontal intermittant rythmic delta acitivityin a patient with auto-immune encephalitis. MRI is normal. The EEG shows repetitive rhythmic slow waves with a frequency $<4 \mathrm{~Hz}$ with a frontal predilection.

1.5 Tesla imaging with 3 or $5 \mathrm{~mm}$ slices, T1 and T2 weighted, Fluidattenuated inversion recovery, and diffusion weighted sequences and had been originally interpreted by a radiologist. All patients had a brain MRI within 24-72 h of EEG acquisition. Each MRI was reviewed by a blinded senior neurologist with advanced experience in MRI evaluation. MRI abnormalities were classified as white matter changes and brain atrophy. Lesion patterns were noted including edema, intracranial hemorrhage, ischemic strokes, or tumors. White matter changes were characterized as mild, moderate and marked [9]: mild for punctate, moderate for beginning confluent, and marked for confluent 
white matter hyperintensities. Brain atrophy was also detected and graded as mild, moderate and marked [10].

\section{Outcome variables}

The princibal outcome measure was th Glascow Outcome Score at discharge, designated as unfavorable (GOS 1-3) and favorable (GOS $>3$ ). Secondary outcome was length of hospital stay.

\section{Statistics}

Statistical analysis was performed with SPSSS version 16.

\begin{tabular}{|c|c|}
\hline Demographics and clinical characteristics & $\begin{array}{l}\text { Number of } \\
\text { patients ( } n: 49)\end{array}$ \\
\hline \multicolumn{2}{|l|}{ Gender } \\
\hline Female ,n (\%) & $23(46.9)$ \\
\hline Male, n (\%) & $26(53.4)$ \\
\hline Mean time between EEG and MRI in days, mean (SD) & $2(1.4)$ \\
\hline GCS at the time of EEG, mean (SD) & $12(2)$ \\
\hline \multicolumn{2}{|l|}{ Principal Diagnosis } \\
\hline Acute lymphoblastic leukemia, drug toxicity & 3 \\
\hline Epilepsy, Drug overdose & 2 \\
\hline Neuroblastom, toxicity & 1 \\
\hline Pre-B acute lymphoblastic leukemia, toxicity & 1 \\
\hline Unknown drug addiction & 1 \\
\hline $\begin{array}{l}\text { Acute myeloblastic leukemia, posterior reversible encephalopa- } \\
\text { thy }\end{array}$ & 1 \\
\hline Epilepsy, hyperammonemia & 2 \\
\hline Head trauma, anoxic & 3 \\
\hline Epilepsy, hyponatremia & 2 \\
\hline Drowning & 1 \\
\hline $\begin{array}{l}\text { Hypomyelination with atrophy of the basal ganglia and } \\
\text { cerebellum (H-ABC) }\end{array}$ & 1 \\
\hline Hepatic encephalopathy & 2 \\
\hline $\begin{array}{l}\text { H1N1 triggered acute necrotizing encepahlopathy with } \\
\text { RANBP2 mutation }\end{array}$ & 1 \\
\hline Acute disseminated encephalomyelitis & 1 \\
\hline Cystinozis & 1 \\
\hline Auto immune encephalitis & 2 \\
\hline Leigh disease & 1 \\
\hline Unknown ınborn error of Metabolic disorder & 2 \\
\hline Congenital adrenal hyperplasia, varicella vasculopathy & 1 \\
\hline Acute myeloblastic leukemia, encephalitis & 2 \\
\hline Epilepsy, pneumonia & 1 \\
\hline Acute gastroenteritis, sepsis & 1 \\
\hline Pontine glioma, sepsis & 1 \\
\hline Burkitt lymphoma, brain abscess & 1 \\
\hline Hemophagocytic lymphohistiositozis, sepsis & 1 \\
\hline Viral encephalitis & 4 \\
\hline Acute lymphoblastic leukemia,sepsis & 4 \\
\hline NonHodgkin lymphoma, sepsis & 3 \\
\hline Medullablastom, sepsis & 1 \\
\hline
\end{tabular}

Table 1: Demographic and clinical characteristics of the patients.
Categorical variables were summarized as counts and proportions, continuous variables as means and standard deviations. According to their EEG patterns, patients were categorized into five groups.Analysis of variance (ANOVA) was used for comparison of continous variables and Pearson Chi-square test was used for categorical variables. Covariates were categorized as structural (i.e., brain abnormalities, such as atrophy, white matter changes, intracerebral hemorrhages,edema) and non-structural (i.e., infections, drug abuse toxic). Univariable logistic regression was used to calculatethe odds of patients' clinical and imaging abnormalities having one of the five EEG patterns.After that, a multivariable analysis was performed or all significant results in the univariable logistic regression. Levels for statistical significance were set at two-tailed $\mathrm{p}$ value of $<0.05$.

\section{Results}

Among 1254 EEGs recorded for at least $20 \mathrm{~min}$ from hospitalized patients, $49(3.81 \%)$ satisfied the above EEG pattern of diffuse encephalopathy. Mean age at the time of hospitalization was $7.27 \pm$ 4.84 ( 1 year-17 years) with 26 males and 23 females. The majority of patients (94\%) were in the Pediatric Intensive Care Unit PICU, while all other patients were hospitalized on other pediatric wards. The mean of the lowest GCS on the day of EEG recording was $12( \pm 2)$. Patients presented with either loss of conciousness, headache or seizure. All patients had a brain imaging by 1.5 T MRI. Mean time between EEG and MRI was $2 \pm 1.4$ days.

The most common EEG finding in pediatric encephalopathy was isolated continuous slowing of background activity (91.9\%). The theta pattern was present in $32.7 \%$ (n:16) of patients, 34.7\% (n:17) had theta/ delta, $24.5 \%$ (n:12) delta, $4.1 \%$ (n: 2) with FIRDA and two patients had TW. The patient with TW had theta/delta background activity. Of the 2 patients with FIRDA one had a theta background activity, whereas the other had theta/delta activity and both had alpha activity intrusions. Delta activity was linked to toxic encephalopathy group, whereas theta/ delta with the infectious group. Comparison of demographics and clinical characteristics between the five groups are shown in Table 2. Age in patients with FIRDA are significantly older, whereas delta being younger. Patients with delta and theta/delta pattern have significantly lower GCS than others $(\mathrm{p}<0.002)$.

Cranial MRI was performed in all patients. Brain imaging was normal in 8 patients. The most common structural abnormalities were white matter changes (\% 57.1), followed by non-structural problems such as metabolic problems (40.8\%) and infections (38\%). Four patients had mild and one patient had moderate atrophy, five patients had edema, three patients intracranial hemorhaggea. Eight patients (16.3\%) had edema and white matter changes, seven had atrophy and white matter changes. Overall, $67 \%$ had one or two of these abnormalities.

A multivariate analysis for the association of brain imaging abnormalities, non-structural problems and particular EEG patterns were performed (Table 3 ). Theta pattern was significantly associated

\begin{tabular}{|c|c|c|c|c|c|c|}
\hline Demographics & Theta & Theta/delta & Delta & Triphasic waves & FIRDA & p value \\
\hline & $(n: 16)$ & (n: 17) & (n: 12) & (n: 2) & (n: 2) & \\
\hline \multicolumn{7}{|l|}{ Gender } \\
\hline Female & 9 & 7 & 5 & 1 & - & 0.321 \\
\hline Male & 7 & 10 & 7 & 1 & 2 & \\
\hline Age & $10.2 \pm 2.8$ & $11.9 \pm 2.1$ & $4.6 \pm 1.2$ & $11.5 \pm 3.5$ & $12.5 \pm 4.2$ & 0.002 \\
\hline Glascow Coma Scale & 11 & 8 & 8 & 10 & 14 & 0.036 \\
\hline
\end{tabular}

Table 2: Demographic and clinical features of the patients in different EEG patterns in encephalopathy ( $\mathrm{n}$ : 49) (Bold $\mathrm{p}$ values: significant). 
Citation: Arhan E, Akbas Y, Aydın K, Hırfanoglu T, Serdaroglu A, et al. (2016) Electroencephalography and Braın Imagıng Patterns in Chıldren with Acute Encephalopathy. J Neurol Neurophysiol 7: 378. doi:10.4172/2155-9562.1000378

Page 5 of 7

\begin{tabular}{|c|c|c|c|}
\hline Abnormalities/EEG patterns & OR & $95 \% \mathrm{Cl}$ & $\mathrm{p}$ value \\
\hline \multicolumn{4}{|l|}{ Brain atrophy } \\
\hline Theta & 2.1 & $1.41-5.98$ & 0.02 \\
\hline Theta/delta & 1.1 & $0.51-1.92$ & 0.54 \\
\hline Delta & 0.9 & $0.41-1.92$ & 0.72 \\
\hline FIRDA & - & No patients & \\
\hline TW & - & No patients & \\
\hline \multicolumn{4}{|l|}{ Toxic encephalopathy } \\
\hline Theta & 3.4 & $1.48-8.75$ & 0.03 \\
\hline Theta/delta & 0.8 & $0.41-2.01$ & 0.644 \\
\hline Delta & 0.3 & $0.1-1.34$ & 0.054 \\
\hline FIRDA & - & No patients & \\
\hline TW & 0.1 & $0.05-0.2$ & 0.412 \\
\hline \multicolumn{4}{|l|}{ Viral encephalitis } \\
\hline Theta & 0.4 & $0.05-4.32$ & 0.520 \\
\hline Theta/delta & 6.8 & $1.78-18.60$ & 0.005 \\
\hline Delta & 0.5 & $0.06-4.12$ & 0.511 \\
\hline FIRDA & - & No patients & \\
\hline TW & - & No patients & \\
\hline \multicolumn{4}{|l|}{$\begin{array}{l}\text { White matter diffusion signal } \\
\text { abnormality }\end{array}$} \\
\hline Theta & 0.4 & $0.05-3.06$ & 0.362 \\
\hline Theta/delta & 7.4 & $1.18-15.90$ & 0.039 \\
\hline Delta & 1.6 & $0.62-3.74$ & 0.287 \\
\hline FIRDA & 0.3 & $0.06-1.14$ & 0.070 \\
\hline TW & 0.4 & $0.05-3.02$ & 0.359 \\
\hline \multicolumn{4}{|l|}{ Drug abuse or intoxication } \\
\hline Theta & 0.5 & $0.24-1.98$ & 0.540 \\
\hline Theta/delta & 0.3 & $0.08-1.15$ & 0.075 \\
\hline Delta & 3.29 & $1.41-7.88$ & 0.02 \\
\hline FIRDA & - & No patients & \\
\hline TW & - & No patients & \\
\hline \multicolumn{4}{|l|}{ Metabolic disorders } \\
\hline Theta & 1.0 & $0.42-2.24$ & 0.854 \\
\hline Theta/delta & 2.1 & $0.80-3.24$ & 0.072 \\
\hline Delta & 2.8 & $1.28-6.34$ & 0.02 \\
\hline FIRDA & - & No patients & \\
\hline TW & 0.3 & $0.06-1.12$ & 0.068 \\
\hline
\end{tabular}

Table 3: Associations between MRI abnormalities, non-structual problems and EEG patterns. (Bold $p$ values: significant)

with brain atrophy and with toxic encephalopathy (OR $2.195 \% \mathrm{CI}$ 1.41-5.98 p: 0.02, 0R $3.495 \% 1.48-8.75$ p: 0.03 ), theta/delta pattern with white matter abnormalities and viral encephalitis (OR 7.4, 95\% CI 1.18-15.90, p: 0.039 and OR 6.8, 95\% CI 1.78-18.60, p: 0.005), delta activity was linked to drug intoxication (OR 3.2, 95\% CI 1.417.88, p: 0.02) and metabolic disorders (OR 2.8 95\% CI 1.28-6.34 p: 0.02). Subgroup analysis for patients who have FIRDA and TW was nor possible because of the small number of patients. There were two patients who have FIRDA on EEG. One was a 16 year old boy who was referred for encephalopathy and generalized seizure im whom EEG was performed on the first day. The second patient was also referred for acute encephalopathy and orofacial dyskinesia, Both patients who had FIRDA were diagnosed with auto-immune encephalitis,whereas patients with TWs were followed with hepatic encephalopathy and had brain edema.

Patients with a theta/delta pattern was more likely require intensive care others (OR 4.5, 95\% CI 1.74-12.42, p:0.002), whereas those with FIRDA didn't need PICU-treatment. Compared to patients with other EEG patterns, length of hospital stay was prolonged in the patients with delta pattern (p: 0.001)

Short term outcomes of the patients are shown in Table 4. Theta/ delta pattern was associated with the most unfavorable outcome (GOS 1-3) (OR 2.3, 95\% CI 1.78-6.21, p: 0.033) while patients with FIRDA have a favorable outcome.

\section{Discussion}

In patients with encephalopathy, when added on the clinical picture, EEG and brain imaging may distinctly enhance diagnosis and have a prognostic value. So far, experimental studies in animals have been performed to show the correlation between clinical features, EEG patterns and neuroaxial localization. Similar studies in adult studies have been inferred for EEG patterns and imaging correlation $[2,5,6]$. The current study is the first ever that included a pediatric group comprising patients with diffuse encephalopathy. In this study, we evaluated the EEG, brain imaging and clinical data of a cohort of pediatric cases (patients with encephalopathy on EEG) to evaluate the etiological profile, EEG patterns and brain imaging findings seen in encephalopathy.

The most common EEG pattern is isolated continuous slowing of background activity, seen in $91.9 \%$ of our patients, as previously reported in adult studies $[5,11,12]$. The most frequent medical conditions were metabolic problems, infections and white matter changes. Most of the patients $(67 \%)$ had two or more of these abnormalities.

We found associations between EEG patterns and structural

\begin{tabular}{|c|c|c|c|c|c|}
\hline $\begin{array}{l}\text { Pediatric Intensive } \\
\text { Care Unit Requirement }\end{array}$ & $\mathbf{n}$ & $\%$ & OR & $95 \% \mathrm{Cl}$ & $p$ value \\
\hline Theta & 4 & 22 & 1.8 & $0.74-4.2$ & 0.226 \\
\hline Theta/delta & 11 & 71 & 4.5 & $1.74-12.42$ & 0.002 \\
\hline Delta & 5 & 41 & 2.1 & $0.90-4.81$ & 0.088 \\
\hline FIRDA & 0 & 0 & - & - & - \\
\hline TW & 1 & 3 & 0.6 & $0.08-3.42$ & 0.412 \\
\hline \multicolumn{6}{|l|}{ GOS (categorical) } \\
\hline \multicolumn{6}{|l|}{ GOS $>3$} \\
\hline Theta & 4 & 25 & 1.4 & $0.54-2.56$ & 0.662 \\
\hline Theta/delta & 5 & 56 & 0.5 & $0.14-1.92$ & 0.689 \\
\hline Delta & 5 & 22 & 2.7 & $0.90-5.81$ & 0.088 \\
\hline FIRDA & 2 & 100 & 4.1 & $1.62-12.5$ & 0.004 \\
\hline TW & 1 & 33 & 0.6 & $0.08-3.42$ & 0.412 \\
\hline \multicolumn{6}{|l|}{ GOS 1-3 } \\
\hline Theta & 3 & 50 & 0.8 & $0.36-2.01$ & 0.692 \\
\hline Theta/delta & 5 & 65 & 2.3 & $1.78-6.21$ & 0.033 \\
\hline Delta & 4 & 43 & 1.2 & $0.45-2.81$ & 0.748 \\
\hline FIRDA & 0 & 0 & - & - & - \\
\hline TW & 1 & 50 & - & - & - \\
\hline Length of hospital stay & Mean \pm SD & $p$ value & & & \\
\hline Theta & $17.8 \pm 3.2$ & 0.345 & & & \\
\hline Theta/delta & $14.5 \pm 2.8$ & 0.955 & & & \\
\hline Delta & $23.4 \pm 4.6$ & 0.001 & & & \\
\hline FIRDA & $13.4 \pm 2.1$ & 0.040 & & & \\
\hline TW & $18.2 \pm 2.5$ & 0.780 & & & \\
\hline
\end{tabular}

Table 4: Course and short term outcomes of the patients ( $n: 49)$ (Bold $p$ values: significant). 
and non-structural abnormalities and early outcome parameters. A dominant delta activity was linked to toxic etiology, theta/delta with the infectious etiology. Theta pattern was significantly associated with brain atrophy and toxic entiology, theta/delta pattern with white matter abnormalities and viral encephalitis, delta activity was linked to drug intoxication and metabolic disorders. Our results pointed out a clinical outline for interpreting several commonly described EEG patterns in children with encephalopathy.

Similar to our results, in a previous study, significant associations of of intracranial hemorrhage, posterior reversible encephalopathy, or infection with slow background activity has been reported [6]. This may be attributed to the possible correlates of the pathologic changes in the thalamocortical circuits that underlie cortical slowing. The co-occurrence of structural and non-structural problems such as infections and metabolic problem was seen in nearly half of the patients. This underlines the importance of the interference of the etiological factors in the genesis of encephalopathy. Unfortunately, because of the retrospective design of the study, additional pathological conditions such as acute changes of blood flow and intracranial pressure could not be assessed, this may lead to a larger proportion of patients with cooccurring pathological conditions. Prospective studies would help to highlight EEG alterations in these acute medical conditions and may give a prognostic information of EEG.

The associations of specific EEG patterns with different pathological conditions have been previously described with TWs and FIRDA $[1,6,13,14]$. To our knowledge, our finding of FIRDA seen in auto-immune encephalitis has not been previously demonstrated. Earlier studies have revealed a great variety of conditions that could be associated with FIRDA, including, tumors [15], subcortical lesions [16], brain edema [13], encephalitis [17]. This may indicate that FIRDA has no significant association with structural or non-structural abnormalities, and mostly have a favaorable outcome. TWs are thougt to reflect thalamo-cortical circuits which also underlie generalized epileptiform discharges and sleep spindle activity. These structures may be modified by subcortical white matter disease caused by ischemic or degenerative processes $[18,19]$ and this leads to projected slow activity. In our group, there were only two patients with TWs and both had hepatic encephalopathy with brain edema. This may assert that structural abnormalities may enable projected slower activity (delta activity or TWs). An accurate and isolated association of hepatic encephalopathy with the appereance of TWs could not be claimed due to the small number of patients.

We have linked the EEG patterns to the clinical outcomes of the patients. Theta/delta pattern was associated with unfavorable outcome, while favorable outcome was seen in patients with FIRDA. A faster background activity with FIRDA and higher GCS may be the explanation of the favorable outcome in these patients. Marchetti et al. [20] previously demonstrated the associations of EEG abnormalities with outcomes in hospitalized patients with hepatic encephalopathy and TWs and described an inverse correlation of decreasing EEG frequency in patients with cirrhosis and survival. Sutter et al [6] reported a favorable prognosis for patients with FIRDA. Both studies are consistent with our findings.

Our study was limited by its retrospective nature, small sample size, and heterogenity. The retrospective nature of the study restricts the timing and evolution of certain diagnoses in relation to the onset of encephalopathy, its duration and severity could not be determined from the hospital data reviewed and a consequent lack of longer followup EEGs in most cases limits sufficient further analysis. Prospective studies of a repeat EEG after resolution of the acute encephalopathy would be beneficial in this context. Another limitation is the size of the subgroups. This is because of the single center design. Our patients are highly selective which limits generalizability of pediatric encephalopathic patients with other EEG patterns. Patients may present with co-occurring structural and non-structural disorders or may have a number of transient abnormalities together. A large number of patient groups are required for such an analysis. Therefore, this study may not solely determine the specific and isolated conditions which had a causal role in the development of EEGdisturbances.

\section{Conclusion}

The most common EEG finding in patients with encephalopathy is isolated continuous slowing of background activity. These patterns are associated with specific structural or non-structural pathological conditions. Although these conditions have a high rate of co-occurrence, EEG and brain imaging taken together might lead clinicians towards a probable cause of encephalopathy. This study, which to the best of our knowledge is the first of its kind in the pediatric age group suggest some associations. Continuous EEG monitoring of patients with encephalopathy is required to clarify these findings in addition to the outcomes.

\section{References}

1. Accolla EA, Kaplan PW, Maeder-Ingvar M, Jukopila S, Rossetti AO (2011) Clinical correlates of frontal intermittent rhythmic delta activity (FIRDA). Clin Neurophysiol 122: 27-31.

2. Cissé $Y$, Wang S, Inoue I, Kido H (2010) Rat model of influenza-associated encephalopathy (IAE): Studies of electroencephalogram (EEG) in vivo. Neuroscience 165: 1127-1137.

3. Gloor P, Ball G, Schaul N (1977) Brain lesions that produce delta waves in the EEG. Neurology 27: 326-333.

4. Kaplan PW, Rossetti AO (2011) EEG patterns and imaging correlations in encephalopathy: Encephalopathy part II. J Clin Neurophysiol 28: 233-251.

5. Wabulya A, Lesser RP, Llinas R, Kaplan PW (2016) Electroencephalography and brain MRI patterns in encephalopathy. Clin EEG Neurosci 47: 150-156.

6. Sutter R, Stevens RD, Kaplan PW (2013) Clinical and imaging correlates of EEG patterns in hospitalized patients with encephalopathy. J Neurol 260: 10871098.

7. Fisch BJ (1999) Electrographic seizure patterns, pseudoperiodic patterns, and pseudoepileptiform patterns. In: Fisch BJ (edn) Fisch and Spehlmann's EEG Primer: basic principles of digital and nanalog EEG. Elsevier, Amsterdam pp 328-331.

8. Foley JM, Watson CW, Adams RD (1950) Significance of the electroencephalographic changes in hepatic coma. Trans Am Neurol Assoc 51 161-165.

9. Barkovich AJ (1988) Techniques and methods in pediatric magnetic resonance imaging. Semin Ultrasound CT MR 9: 186-191.

10. Barkovich AJ, Maroldo TV (1993) Magnetic resonance imaging of normal and abnormal brain development. Top Magn Reson Imaging 5: 96-122.

11. Benatar M, Drislane FW (2005) Encephalopathy as a mimic of seizures. In Kaplan PW, Fisher RS. Imitators of Epilepsy 2nd edn. New York, NY: Demos Medical, pp 191-203.

12. Gloor P, Ball G, Schaul N (1977) Brain lesions that produce delta waves in the EEG. Neurology 27: 326-333.

13. Gastaut JL, Michel B, Hassan SS, Cerda M, Bianchi L, et al. (1979) Electroencephalography in brain edema (127 cases of brain tumor investigated by cranial computerized tomography). Electroencephalogr Clin Neurophysiol 46: 239-255.

14. Watemberg N, Alehan F, Dabby R, Lerman-Sagie T, Pavot P, et al. (2002) Clinical and radiologic correlates of frontal intermittent rhythmic delta activity. $J$ Clin Neurophysiol 19: 535-539. 
Citation: Arhan E, Akbas Y, Aydın K, Hırfanoglu T, Serdaroglu A, et al. (2016) Electroencephalography and Braın Imagıng Patterns in Chıldren wıth Acute Encephalopathy. J Neurol Neurophysiol 7: 378. doi:10.4172/2155-9562.1000378

Page 7 of 7

15. Faure J, Droogleever-Fortuyn J, Gastaut H, Larramendi L, Martin P, et al (1951) Genesis and significance of rhythms recorded at a distance in cases of cerebral tumors. Electroencephalogr Clin Neurophysiol 3: 429-434.

16. Jasper H, Van Buren J (1955) Interrelationship between cortex and subcortical structures: clinical electroencephalographic studies. Electroencephalogr Clin Neurophysiol Suppl 4: 168-188.

17. Fariello RG, Orrison W, Blanco G, Reyes PF (1982) Neuroradiological correlates of frontally predominant intermittent rhythmic delta activity (FIRDA). Electroencephalogr Clin Neurophysiol 54: 194-202.
18. Karnaze DS, Bickford RG (1984) Triphasic waves: A reassessment of their significance. Electroencephalogr Clin Neurophysiol 57: 193-198.

19. Sundaram MB, Blume WT (1987) Triphasic waves: Clinical correlates and morphology. Can J Neurol Sci 14: 136-140.

20. Marchetti P, D'Avanzo C, Orsato R, Montagnese S, Schiff S, et al. (2011) Electroencephalography in patients with cirrhosis. Gastroenterology 141: 16801689. 